\title{
Thresholds of various glycemic measures for diagnosing diabetes based on prevalence of retinopathy in community-dwelling Japanese subjects: the Hisayama Study
}

Naoko Mukai ${ }^{1,2^{*}}$, Miho Yasuda ${ }^{3}$, Toshiharu Ninomiya ${ }^{1,2}$, Jun Hata ${ }^{1,2}$, Yoichiro Hirakawa ${ }^{1,2}$, Fumie Ikeda ${ }^{1,2}$, Masayo Fukuhara ${ }^{1,2}$, Taeko Hotta ${ }^{4}$, Masafumi Koga ${ }^{5}$, Udai Nakamura ${ }^{2}$, Dongchon Kang ${ }^{4}$, Takanari Kitazono ${ }^{2}$ and Yutaka Kiyohara ${ }^{1}$

\begin{abstract}
Background: There has been controversy over the diagnostic thresholds of hemoglobin $A_{1 c}\left(H b A_{1 c}\right)$ for diabetes. In addition, no study has examined the thresholds of glycated albumin (GA) and 1,5-anhydroglucitol (1,5-AG) for diagnosing diabetes using the presence of diabetic retinopathy (DR). We examined the optimal thresholds of various glycemic measures for diagnosing diabetes based on the prevalence of DR in community-dwelling Japanese subjects.

Methods: A total of 2,681 subjects aged 40-79 years underwent a 75-g oral glucose tolerance test, measurement of $\mathrm{HbA}_{1 c}, \mathrm{GA}$, and 1,5-AG, and an ophthalmic examination in 2007-2008. The associations of glycemic measures with DR status were examined cross-sectionally. DR was assessed by an examination of the fundus photograph of each eye and graded according to the International Clinical Diabetic Retinopathy Disease Severity Scale. We divided the values of glycemic measures into ten groups on the basis of deciles. The receiver operating characteristic (ROC) curve analysis was performed to determine the optimal threshold of each glycemic measure for detecting the presence of DR.

Results: Of the subjects, 52 had DR. The prevalence of DR increased steeply above the ninth decile for fasting plasma glucose (FPG) (6.2-6.8 mmol/l), for 2-hour postload glucose (PG) $(9.2-12.4 \mathrm{mmol} / \mathrm{l})$, for $\mathrm{HbA}_{1 \mathrm{c}}(5.9-6.2 \%$ [41-44 mmol/mol]), and for GA (16.2-17.5\%), and below the second decile for 1,5-AG (9.6-13.5 $\mu \mathrm{g} / \mathrm{mL})$. The ROC curve analysis showed that the optimal thresholds for DR were $6.5 \mathrm{mmol} / \mathrm{l}$ for FPG, $11.5 \mathrm{mmol} / \mathrm{l}$ for 2-hour PG, $6.1 \%$ (43 mmol/mol) for $\mathrm{HbA}_{1,}, 17.0 \%$ for GA, and $12.1 \mu \mathrm{g} / \mathrm{mL}$ for 1,5-AG. The area under the ROC curve (AUC) for 2-hour PG (0.947) was significantly larger than that for FPG (0.908), GA (0.906), and 1,5-AG (0.881), and was marginally significantly higher than that for $\mathrm{HbA}_{1 \mathrm{c}}$ (0.919). The AUCs for FPG, $\mathrm{HbA}_{1 c}, \mathrm{GA}$, and 1,5-AG were not significantly different.

(Continued on next page)
\end{abstract}

\footnotetext{
* Correspondence: n-mukai@envmed.med.kyushu-u.ac.jp

${ }^{1}$ Department of Environmental Medicine, Graduate School of Medical

Sciences, Kyushu University, 3-1-1 Maidashi, Higashi-ku, Fukuoka 812-8582,

Japan

${ }^{2}$ Department of Medicine and Clinical Science, Graduate School of Medical

Sciences, Kyushu University, Fukuoka, Japan

Full list of author information is available at the end of the article
} 
(Continued from previous page)

Conclusions: Our findings suggest that the FPG and $\mathrm{HbA}_{1 c}$ thresholds for diagnosing diabetes in the Japanese population are lower than the current diagnostic criterion, while the 2-hour PG threshold is comparable with the diagnostic criterion. 2-hour PG had the highest discriminative ability, whereas FPG, HbA ${ }_{1 c}$, GA, and 1,5-AG were similar in their ability.

Keywords: Diagnostic criteria, Hemoglobin $A_{1 c}$, Glycated albumin, 1,5-anhydroglucitol, Fasting plasma glucose, 2-hour postload glucose, Retinopathy

\section{Background}

The International Expert Committee [1,2], the American Diabetes Association [3], and the World Health Organization [4] recently proposed the use of hemoglobin $\mathrm{A}_{1 \mathrm{c}}\left(\mathrm{HbA}_{1 \mathrm{c}}\right)$ to diagnose diabetes at a threshold of $6.5 \%(48 \mathrm{mmol} / \mathrm{mol})$. This threshold was based primarily on the findings of several epidemiological studies in Western populations that investigated $\mathrm{HbA}_{1 \mathrm{c}}$ levels associated with a higher prevalence of diabetic retinopathy (DR), the most specific microvascular complication of diabetes [5-7]. It has been reported that a higher $\mathrm{HbA}_{1 \mathrm{c}}$ level was significantly associated with $\mathrm{DR}$ in subjects with diabetes [8], and some clinical trials have demonstrated that lowering $\mathrm{HbA}_{1 \mathrm{c}}$ levels decreased the risk of microvascular complications, such as DR, in diabetes patients [9-11]. These findings suggest that $\mathrm{HbA}_{1 \mathrm{c}}$ levels are intimately related to the risk of $\mathrm{DR}$, and this evidence supports the use of $\mathrm{HbA}_{1 \mathrm{c}}$ as a diagnostic tool for diabetes. However, there has been controversy over the diagnostic threshold of $\mathrm{HbA}_{1 \mathrm{c}}$. An integrated study of three general populations has shown that the relation between fasting plasma glucose (FPG) levels and the prevalence of retinopathy was continuous, with no clear threshold [12], whereas a prospective study of a French population recently revealed that the optimal threshold of $\mathrm{HbA}_{1 \mathrm{c}}$ for incident retinopathy was $6.0 \%$, which is below the current diagnostic criterion [13]. In addition, several cross-sectional studies of Asian populations, including our previous study, have examined this issue [14-18], but the optimal $\mathrm{HbA}_{1 \mathrm{c}}$ thresholds have differed among these investigations. Thus, a reevaluation of threshold of $\mathrm{HbA}_{1 \mathrm{c}}$ for $\mathrm{DR}$ is needed.

Glycated albumin (GA) and 1,5-anhydroglucitol (1,5AG) levels, which are serum markers of hyperglycemia, have also been found to be significantly associated with microvascular complications $[19,20]$. There have been a few studies investigating GA [21-23] and 1,5-AG levels [24-26] to detect subjects with glucose intolerance defined by glucose levels, but no study has examined the diagnostic thresholds of these glycemic measures for diabetes based on the presence of DR, and it is uncertain whether GA and 1,5-AG measurements are applicable as a diagnostic tool for diabetes $[27,28]$. In addition, in the general Asian community, there are limited data assessing FPG and 2-hour postload glucose (PG) levels associated with the prevalence of DR $[14,17,29]$.
The purposes of this study were to determine the thresholds of FPG, 2-hour PG, $\mathrm{HbA}_{1 \mathrm{c}}$, GA, and 1,5-AG for the diagnosis of diabetes based on the prevalence of DR in a community-dwelling Japanese population, and to compare the ability of these five glycemic measures to differentiate subjects with and without DR.

\section{Methods}

\section{Study population}

A population-based prospective study of cardiovascular disease and its risk factors has been underway since 1961 in the town of Hisayama, a suburb of the Fukuoka metropolitan area on Japan's Kyushu Island. The population of the town has been stable for 50 years and was approximately 8,400 in 2010 . The age and occupational distributions, and nutritional intake of the population were similar to those of Japan as a whole based on data from the national census and nutrition survey [30,31]. In 2007 and 2008, a cross-sectional survey for the present study was performed in the town. A detailed description of this survey was published previously [30]. There were a total of 3,835 residents aged 40-79 years based on the town registry, and 2,957 (participation rate, 77.1\%) took part in a comprehensive assessment, including a 75-g oral glucose tolerance test (OGTT), the measurement of $\mathrm{HbA}_{1 \mathrm{c}}$, and an ophthalmic examination. We excluded the eight subjects who did not consent to participate in the study, 46 who had already had breakfast, 35 who were on insulin therapy, and 156 who refused the OGTT, leaving a total of 2,712 subjects who completed both the 75-g OGTT and $\mathrm{HbA}_{1 \mathrm{c}}$ measurement. Among these, 21 subjects who lacked ophthalmic examination information and 10 for whom there was no measurement of GA or 1,5-AG were excluded, and the remaining 2,681 subjects (1,192 men, 1,489 women) were enrolled in the present study.

\section{Clinical evaluation and laboratory measurements}

The study subjects underwent the OGTT between 8:00 and 10:30 A.M. after an overnight fast of at least 12 hours. Blood for the glucose assay was obtained by venipuncture into tubes containing sodium fluoride at fasting and at 2-hour postload, and was separated into plasma and blood cells within 20 min. Plasma glucose 
concentrations were determined by the hexokinase method. According to the 1998 World Health Organization criteria [32], diabetes was defined as FPG $\geq 7.0 \mathrm{mmol} / \mathrm{l}$ or 2-hour PG $\geq 11.1 \mathrm{mmol} / \mathrm{l}$ or both, or the use of antidiabetic medications. Those who were diagnosed with diabetes with or without treatment before the examination were considered to be cases of known diabetes. Blood samples were also collected for the determination of $\mathrm{HbA}_{1 \mathrm{c}}$ levels, hemoglobin $(\mathrm{Hb})$ and serum creatinine concentrations. $\mathrm{HbA}_{1 \mathrm{c}}$ levels were measured by latex aggregation immunoassay (Determiner HbA1C; Kyowa Medex, Tokyo, Japan). The values for $\mathrm{HbA}_{1 \mathrm{c}}$ were estimated as a National Glycohemoglobin Standardization Program (NGSP) equivalent value calculated with the formula: $\mathrm{HbA}_{1 \mathrm{c}}(\%)=1.02 \times \mathrm{HbA}_{1 \mathrm{c}}$ (Japan Diabetes Society [JDS]) $(\%)+0.25 \%$ [33]. A portion of each serum specimen was stored at $-80^{\circ} \mathrm{C}$ for 5 years until it was used for measurement of GA and 1,5-AG in 2012. Serum GA levels were determined by an enzymatic method using an albuminspecific proteinase, ketoamine oxidase, and an albumin assay reagent (Lucica GA-L; Asahi Kasei Pharma, Tokyo, Japan). Serum 1,5-AG concentrations were measured enzymatically (Lana 1,5AG Auto Liquid; Nippon Kayaku, Tokyo, Japan). Hb concentrations were measured by sodium lauryl sulfate-hemoglobin method. Anemia was defined as $\mathrm{Hb}<13.0 \mathrm{~g} / \mathrm{dL}$ for men and $<12.0 \mathrm{~g} / \mathrm{dL}$ for women [34]. Serum creatinine concentrations were measured enzymatically, and estimated glomerular filtration rate (eGFR) was calculated using the following new Japanese equation: eGFR $\left(\mathrm{mL} / \mathrm{min} / 1.73 \mathrm{~m}^{2}\right)=194 \times($ serum creatinine $[\mathrm{mg} / \mathrm{dL}])^{-1.094} \times(\text { age [years] })^{-0.287} \times(0.739$ if female $)$ [35] Renal failure was defined as an eGFR $<30 \mathrm{~mL} / \mathrm{min} /$ $1.73 \mathrm{~m}^{2}$ (chronic kidney disease stage 4 or 5) [36].

The height and weight were measured with the subject in light clothes without shoes, and the body mass index (BMI) $\left(\mathrm{kg} / \mathrm{m}^{2}\right)$ was calculated. Each participant completed a self-administered questionnaire covering medical history and antidiabetic treatment.

\section{Ophthalmic examination and definition of diabetic retinopathy}

The methods used for the ophthalmic examination have been described in detail previously [14]. Briefly, each participant underwent fundus photographs for the assessment of DR. After pupil dilatation with $1.0 \%$ tropicamide and $10 \%$ phenylephrine, fundus photographs $\left(45^{\circ}\right)$ were taken from both eyes of each participant using a Topcon digital TRC NW-6SF fundus camera (Topcon Corporation, Tokyo, Japan). The photographs were taken in 1-field per eye, centered on the macula. The photographs were assessed by photographic graders who were masked to the clinical information. The severity of DR was classified into 5 categories according to the International Clinical Diabetic Retinopathy Disease Severity
Scale: no retinopathy (equivalent to the Early Treatment of Diabetic Retinopathy Study [ETDRS] scale level 10), mild nonproliferative DR (equivalent to ETDRS level 20), moderate nonproliferative DR (equivalent to ETDRS levels 35, 43, and 47), severe nonproliferative DR (equivalent to ETDRS levels 53A-53E), and proliferative DR (equivalent to ETDRS levels 61 or higher) [37]. The degree of DR was determined according to the grading in the worse eye. The presence of DR was defined as the presence of mild or moderate or severe nonproliferative DR, or proliferative DR in either eye.

\section{Statistical analysis}

The SAS software package version 9.3 (SAS Institute, Cary, NC) was used to perform all statistical analyses. We assessed the statistical significance of differences in the prevalence or mean of each factor among the DR status groups by using a logistic or linear regression model, respectively. To analyze FPG, 2-hour PG, $\mathrm{HbA}_{1 \mathrm{c}}$, GA, and 1,5-AG levels as categorical variables, these values were divided into ten groups on the basis of deciles. The receiver operating characteristic (ROC) curve analysis was performed to determine the optimal threshold of each glycemic measure for detecting the presence of DR. The optimal threshold was obtained from the point on the ROC curve closest to the ideal of $100 \%$ sensitivity and $100 \%$ specificity. The discrimination of each measure of glycemia for DR was assessed by the area under the ROC curve (AUC). The difference in the AUC was estimated using the method of DeLong et al. [38]. A value of $\mathrm{p}<0.05$ was considered statistically significant in all analyses.

\section{Ethical considerations}

This study was conducted with the approval of the Kyushu University Institutional Review Board for Clinical Research, and written informed consent was obtained from all the participants.

\section{Results}

Of the study participants, 52 (1.9\%) had DR. Mild nonproliferative DR, moderate nonproliferative DR, severe nonproliferative DR, and proliferative DR were found in 33 (1.2\%), 6 (0.2\%), $13(0.5 \%)$, and $0(0 \%)$ subjects, respectively. The clinical characteristics of subjects are shown in Table 1 . The mean age of participants was 60 years, and men comprised $44.5 \%$ of the group. The prevalence of diabetes, known diabetes, anemia, and renal failure was $15.2 \%, 10.0 \%, 13.2 \%$, and $0.3 \%$, respectively. The mean values of age, FPG, 2-hour PG, $\mathrm{HbA}_{1 \mathrm{c}}$, $\mathrm{GA}$, diabetes duration and BMI, and the frequencies of men, diabetes, and known diabetes were significantly higher in the subjects with DR than in those without DR, and the subjects with DR had significantly lower 
Table 1 Clinical characteristics of subjects, 2007-2008

\begin{tabular}{|c|c|c|c|c|}
\hline Variable & $\begin{array}{c}\text { Total } \\
(n=2,681)\end{array}$ & $\begin{array}{c}\text { No retinopathy } \\
(n=2,629)\end{array}$ & $\begin{array}{l}\text { Diabetic retinopathy } \\
\qquad(\mathrm{n}=52)\end{array}$ & $p$ value \\
\hline Age (years) & $60(10)$ & $60(10)$ & $67(9)$ & $<0.001$ \\
\hline Men (\%) & 44.5 & 43.9 & 75.0 & $<0.001$ \\
\hline Fasting plasma glucose $(\mathrm{mmol} / \mathrm{l})$ & $5.8(1.1)$ & $5.7(1.0)$ & $8.7(2.5)$ & $<0.001$ \\
\hline 2-hour postload glucose $(\mathrm{mmol} / \mathrm{l})$ & $7.9(3.7)$ & $7.7(3.4)$ & $18.0(5.3)$ & $<0.001$ \\
\hline Hemoglobin $A_{1 c}(\%)$ & $5.5(0.7)$ & $5.5(0.7)$ & $7.4(1.4)$ & $<0.001$ \\
\hline$(\mathrm{mmol} / \mathrm{mol})$ & $37(8)$ & $36(7)$ & $57(15)$ & $<0.001$ \\
\hline Glycated albumin (\%) & $15.2(2.8)$ & $15.1(2.4)$ & $22.7(6.1)$ & $<0.001$ \\
\hline 1,5-anhydroglucitol $(\mu \mathrm{g} / \mathrm{mL})$ & $20.2(8.3)$ & $20.5(8.1)$ & $7.7(7.1)$ & $<0.001$ \\
\hline Diabetic retinopathy (\%) & 1.9 & 0 & 100 & $>0.99$ \\
\hline Diabetes (\%) & 15.2 & 13.6 & 96.2 & $<0.001$ \\
\hline Known diabetes (\%) & 10.0 & 8.3 & 94.2 & $<0.001$ \\
\hline Diabetes duration (years) & $9.5(7.9)$ & $8.3(7.2)$ & $14.8(9.0)$ & $<0.001$ \\
\hline Body mass index $\left(\mathrm{kg} / \mathrm{m}^{2}\right)$ & $23.2(3.4)$ & $23.2(3.4)$ & $24.7(3.6)$ & 0.002 \\
\hline Hemoglobin (g/dL) & $13.6(1.4)$ & $13.6(1.4)$ & $13.9(1.5)$ & 0.09 \\
\hline Anemia (\%) & 13.2 & 13.1 & 17.3 & 0.37 \\
\hline eGFR $\left(\mathrm{mL} / \mathrm{min} / 1.73 \mathrm{~m}^{2}\right)$ & $72.9(13.9)$ & $72.9(13.8)$ & $71.4(18.6)$ & 0.44 \\
\hline Renal failure (\%) & 0.3 & 0.3 & 0 & 0.99 \\
\hline
\end{tabular}

eGFR: estimated glomerular filtration rate. All values are given as the mean (standard deviations) or as a percentage.

Diabetes was defined as fasting plasma glucose of $\geq 7.0 \mathrm{mmol} / \mathrm{l}$, and/or 2 -hour postload glucose of $\geq 11.1 \mathrm{mmol} / \mathrm{l}$, and/or the use of antidiabetic medication. Known diabetes was defined as those who were diagnosed with diabetes with or without treatment before the examination.

Anemia was defined as hemoglobin $<13.0 \mathrm{~g} / \mathrm{dL}$ for men and $<12.0 \mathrm{~g} / \mathrm{dL}$ for women.

Renal failure was defined as an eGFR $<30 \mathrm{~mL} / \mathrm{min} / 1.73 \mathrm{~m}^{2}$

1,5-AG values. The mean values of $\mathrm{Hb}$ and eGFR and the frequencies of anemia and renal failure did not differ between the groups.

Figure 1A shows the prevalence of DR by deciles of the distribution of FPG, 2-hour PG, $\mathrm{HbA}_{1 \mathrm{c}}$, and GA levels. The prevalence of DR was very low in the first through eighth deciles for each glycemic measure, but started to increase steeply from the ninth decile for FPG (6.2-6.8 $\mathrm{mmol} / \mathrm{l})$, 2-hour PG (9.2-12.4 $\mathrm{mmol} / \mathrm{l}), \mathrm{HbA}_{1 \mathrm{c}}$ (5.9-6.2\% [41-44 $\mathrm{mmol} / \mathrm{mol}]$ ), and GA (16.2-17.5\%). Figure $1 \mathrm{~B}$ demonstrates the prevalence of DR by deciles of 1,5-AG levels. The prevalence of DR increased markedly below the second decile for 1,5-AG $(9.6-13.5 \mu \mathrm{g} / \mathrm{mL})$, while there was no apparent increase in the prevalence of DR between the third and the tenth deciles of 1,5-AG.

The optimal thresholds of each glycemic measure for detecting prevalent DR using ROC curve analyses are shown in Table 2. The optimal threshold was $6.5 \mathrm{mmol} / \mathrm{l}$ for FPG, $11.5 \mathrm{mmol} / \mathrm{l}$ for 2-hour PG, 6.1\% (43 mmol/ mol) for $\mathrm{HbA}_{1 \mathrm{c}}, 17.0 \%$ for $\mathrm{GA}$, and $12.1 \mu \mathrm{g} / \mathrm{mL}$ for $1,5-$ AG. The sensitivity, specificity, positive predictive value, and negative predictive value of these thresholds were $82.7 \%, 86.6 \%, 10.9 \%$, and $99.6 \%$ for FPG, $90.4 \%, 89.3 \%$, $14.3 \%$, and $99.8 \%$ for 2 -hour PG, $86.5 \%, 88.8 \%, 13.3 \%$, and $99.7 \%$ for $\mathrm{HbA}_{1 \mathrm{c}}, 86.5 \%, 89.0 \%, 13.5 \%$, and $99.7 \%$ for GA, and $78.8 \%, 85.8 \%, 9.9 \%$, and $99.5 \%$ for $1,5-\mathrm{AG}$, respectively. Among the five glycemic measures, 2-hour PG threshold of $11.5 \mathrm{mmol} / \mathrm{l}$ had the highest sensitivity, while 1,5 -AG threshold of $12.1 \mu \mathrm{g} / \mathrm{mL}$ showed the lowest sensitivity. In addition, with the exception of the thresholds for 2-hour PG and 1,5-AG, the thresholds of the glycemic measures were not substantially changed when DR was defined as a moderate or higher level of retinopathy $(6.5 \mathrm{mmol} / \mathrm{l}$ for $\mathrm{FPG}, 13.1 \mathrm{mmol} / \mathrm{l}$ for 2hour PG, $6.3 \%$ [ $45 \mathrm{mmol} / \mathrm{mol}$ ] for $\mathrm{HbA}_{1 \mathrm{c}}, 17.2 \%$ for GA, and $10.8 \mu \mathrm{g} / \mathrm{mL}$ for $1,5-\mathrm{AG}$ ).

To evaluate the ability of each glycemic measure to identify the presence of DR, we compared the AUC among glycemic measures (Figure 2). The AUC for 2hour PG was 0.947 (95\% confidence interval [CI] 0.9220.971), which was significantly larger than that for FPG (0.908 [95\% CI 0.866-0.949]; $\mathrm{p}=0.01)$, GA (0.906 [95\% CI $0.853-0.960] ; \mathrm{p}=0.03)$, and 1,5 -AG $(0.881$ [95\% CI 0.824$0.937] ; p=0.01$ ), and was marginally significantly higher than that for $\mathrm{HbA}_{1 \mathrm{c}}(0.919$ [95\% CI 0.878-0.959]; $\mathrm{p}=0.07)$. The AUC for 1,5-AG was lower than that for other measures of glycemia, but there was no significant difference in the AUC among FPG, $\mathrm{HbA}_{1 \mathrm{c}}$, GA, and 1,5-AG.

\section{Discussion}

Using data from a cross-sectional survey in a Japanese community, we demonstrated that the optimal thresholds 


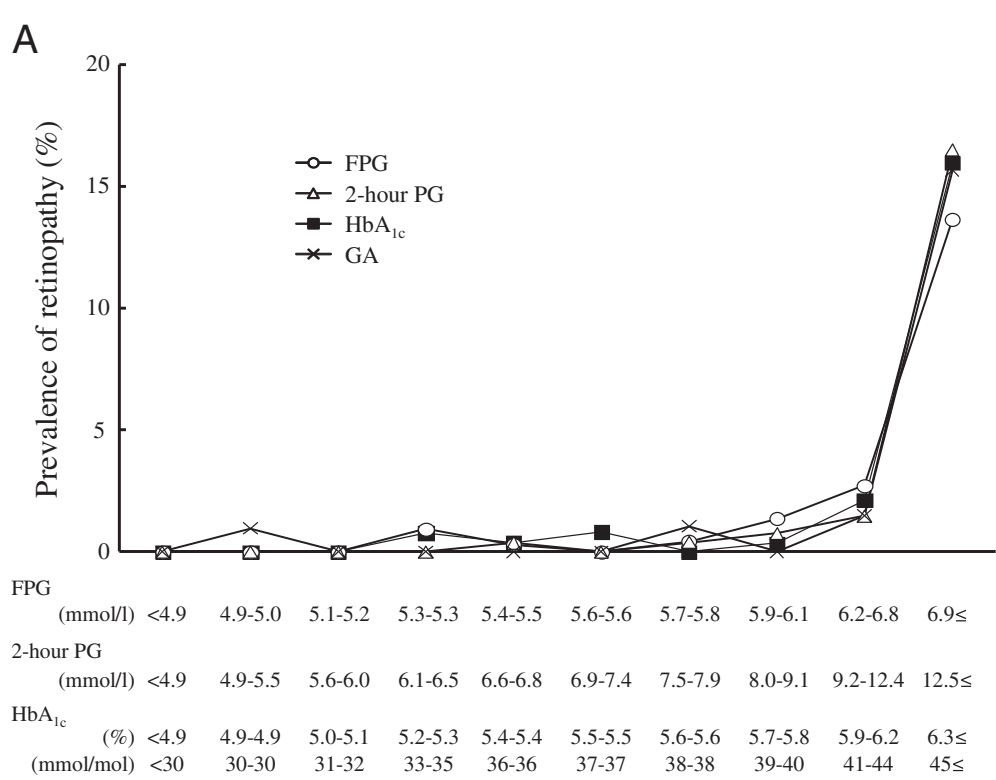

GA

$(\%)<13.0 \quad 13.0-13.6$ 13.7-13.914.0-14.3 14.4-14.6 14.7-15.0 15.1-15.5 15.6-16.1 16.2-17.5 $17.6 \leq$

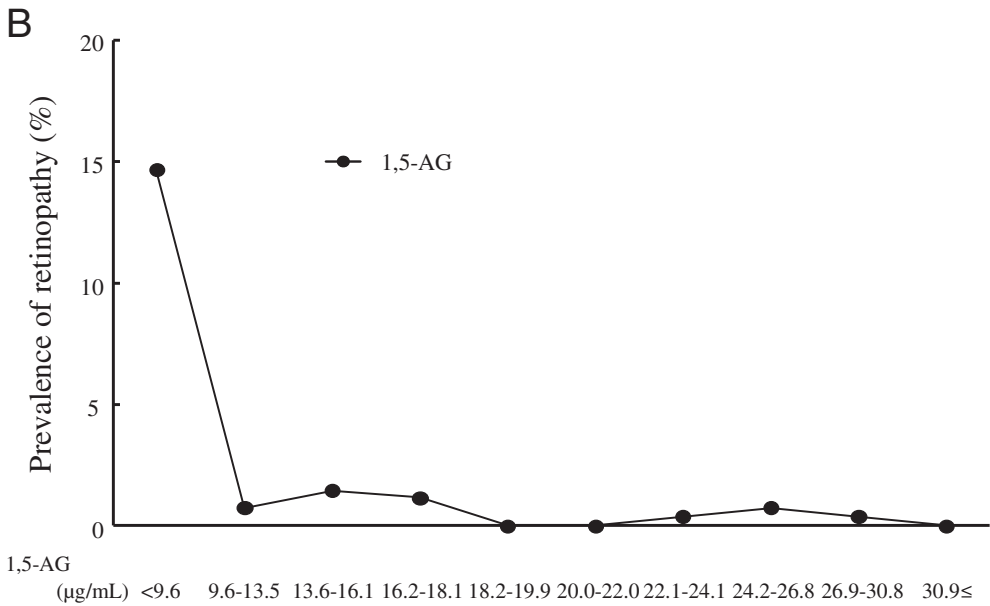

Figure 1 Prevalence of diabetic retinopathy by deciles of the distribution of fasting plasma glucose, 2-hour postload glucose, hemoglobin $A_{1 c}$, glycated albumin (A), and 1,5-anhydroglucitol levels (B). FPG: fasting plasma glucose; 2-hour PG: 2-hour postload glucose; $\mathrm{HbA}_{1 c}$ : hemoglobin $\mathrm{A}_{1 c ;}$ GA: glycated albumin; 1,5-AG: 1,5-anhydroglucitol.

for detecting prevalent DR from ROC analyses were $6.5 \mathrm{mmol} / \mathrm{l}$ for FPG, $11.5 \mathrm{mmol} / \mathrm{l}$ for 2-hour PG, 6.1\% (43 $\mathrm{mmol} / \mathrm{mol}$ ) for $\mathrm{HbA}_{1 \mathrm{c}}, 17.0 \%$ for GA, and $12.1 \mu \mathrm{g} / \mathrm{mL}$ for 1,5 -AG. These results were in accordance with those from the prevalence analysis of DR by decile levels of these measures of glycemia. These findings suggest that the FPG and $\mathrm{HbA}_{1 \mathrm{c}}$ thresholds for diagnosing diabetes in the Japanese population are lower than the current diagnostic criterion, while the 2-hour PG threshold is approximately $11.1 \mathrm{mmol} / \mathrm{l}$, which is comparable to the diagnostic criterion. To our knowledge, the present study is the first report to determine the GA and 1,5-AG thresholds for the diagnosis of diabetes using the prevalence of DR. Furthermore, 2-hour PG had higher sensitivity and larger AUC than other glycemic measures, whereas the AUCs for FPG, $\mathrm{HbA}_{1 \mathrm{c}}$, GA, and 1,5-AG were not significantly different. These findings indicate that 2-hour PG has the highest discriminative ability, and measurements of FPG, $\mathrm{HbA}_{1 \mathrm{c}}, \mathrm{GA}$, and 1,5-AG are similar in their ability.

The $\mathrm{HbA}_{1 \mathrm{c}}$ thresholds for identifying presence of DR have varied among prior epidemiological studies of Asian populations, ranging from $6.1 \%(43 \mathrm{mmol} / \mathrm{mol})$ to $7.0 \%(53 \mathrm{mmol} / \mathrm{mol})$. In a study in a Singapore population, the optimal $\mathrm{HbA}_{1 \mathrm{c}}$ threshold for DR was $6.6-7.0 \%$ (49-53 $\mathrm{mmol} / \mathrm{mol}$ ) [15]. A subanalysis of the DETECT-2, which included three Asian studies in India, Singapore, and Japan, showed that an $\mathrm{HbA}_{1 \mathrm{c}}$ of $6.4 \%(46 \mathrm{mmol} /$ mol) was the optimal threshold [16]. Similar findings 
Table 2 Thresholds of FPG, 2-hour PG, $\mathrm{HbA}_{1 c}, \mathrm{GA}$, and 1,5-AG levels for detecting diabetic retinopathy

\begin{tabular}{lccccc}
\hline & Threshold & $\begin{array}{c}\text { Sensitivity } \\
\text { (\%) }\end{array}$ & $\begin{array}{c}\text { Specificity } \\
\text { (\%) }\end{array}$ & $\begin{array}{c}\text { PPV } \\
\text { (\%) }\end{array}$ & $\begin{array}{c}\text { NPV } \\
\text { (\%) }\end{array}$ \\
\hline FPG & $6.5 \mathrm{mmol} / /$ & 82.7 & 86.6 & 10.9 & 99.6 \\
2-hour PG & $11.5 \mathrm{mmol} / \mathrm{l}$ & 90.4 & 89.3 & 14.3 & 99.8 \\
$\mathrm{HbA}_{1 \mathrm{C}}$ & $6.1 \%(43 \mathrm{mmol} / \mathrm{mol})$ & 86.5 & 88.8 & 13.3 & 99.7 \\
$\mathrm{GA}$ & $17.0 \%$ & 86.5 & 89.0 & 13.5 & 99.7 \\
1,5-AG & $12.1 \mu \mathrm{m} / \mathrm{mL}$ & 78.8 & 85.8 & 9.9 & 99.5 \\
\hline
\end{tabular}

FPG: fasting plasma glucose; 2-hour PG: 2-hour postload glucose; $\mathrm{HbA}_{1 \mathrm{c}}$ : hemoglobin $A_{1 c}$; GA: glycated albumin; 1,5-AG: 1,5-anhydroglucitol; PPV: positive predictive value; NPV: negative predictive value.

The optimal threshold was defined as the point on the receiver operating characteristic curve closest to the ideal of $100 \%$ sensitivity and $100 \%$ specificity. were observed in a Chinese population study $(6.4 \%$ [46 mmol/mol]) [17]. On the other hand, in the present study, the prevalence of DR increased precipitously when $\mathrm{HbA}_{1 \mathrm{c}}$ levels exceeded 5.9-6.2\% (41-44 mmol/ $\mathrm{mol}$ ), and the optimal threshold of $\mathrm{HbA}_{1 \mathrm{c}}$ using the ROC analysis was $6.1 \%(43 \mathrm{mmol} / \mathrm{mol})$. Importantly, this threshold was identical with that from our previous study in 1998 (NGSP: $6.1 \%$ [43 mmol/mol]; JDS: 5.7\%) [14]. Furthermore, in another epidemiological study in a Japanese population, the ROC analysis indicated that the highest precision for $\mathrm{DR}$ was observed at an $\mathrm{HbA}_{1 \mathrm{c}}$ value of $6.2 \%$ ( $44 \mathrm{mmol} / \mathrm{mol})$ [18]. These findings suggest that the $\mathrm{HbA}_{1 \mathrm{c}}$ threshold in the Japanese population was lower than that of other Asians and also lower than the diagnostic criterion of $6.5 \%(48 \mathrm{mmol} / \mathrm{mol})$. Although the reason for this difference is unclear, the influence of race and ethnicity on $\mathrm{HbA}_{1 \mathrm{c}}$ levels may contribute to this phenomenon. Some epidemiological

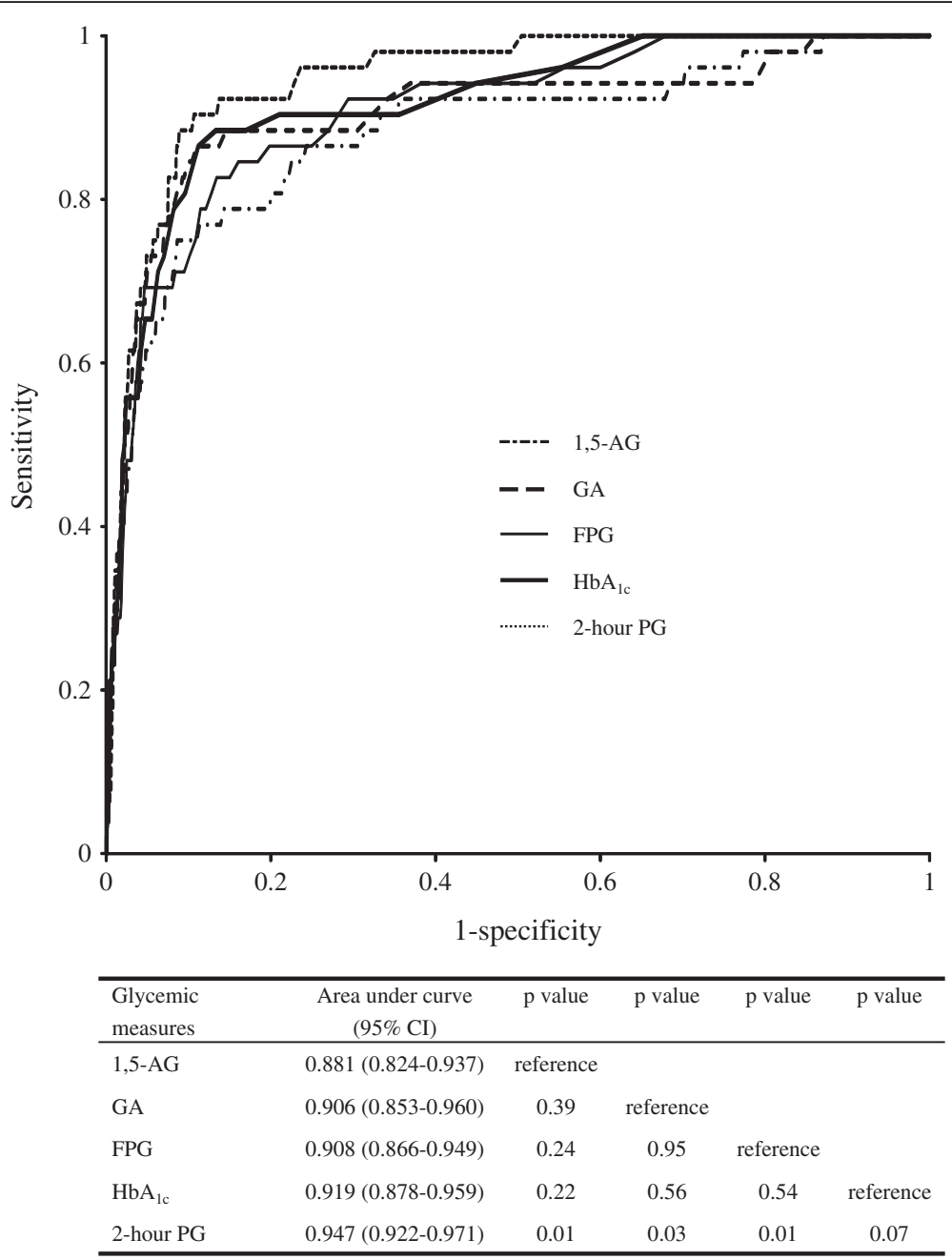

Figure 2 Comparison of the discriminative ability of fasting plasma glucose, 2-hour postload glucose, hemoglobin $A_{1 c}$, glycated albumin, and 1,5-anhydroglucitol for detecting the presence of diabetic retinopathy. FPG: fasting plasma glucose; 2-hour PG: 2-hour postload glucose; $\mathrm{HbA}_{1}$ : hemoglobin $\mathrm{A}_{1}$; GA: glycated albumin; 1,5-AG: 1,5-anhydroglucitol; Cl: confidence interval. 
studies have shown that South Asians, Hispanics, and Blacks had higher $\mathrm{HbA}_{1 \mathrm{c}}$ levels than non-Hispanic whites, independent of glucose $[39,40]$. In our subjects, the mean of $\mathrm{HbA}_{1 \mathrm{c}}$ levels $(5.5 \%$ [37 $\mathrm{mmol} / \mathrm{mol}]$ ) was lower than those in other Asian population studies (6.0$6.5 \%$ [42-48 $\mathrm{mmol} / \mathrm{mol}]$ ) [15-17]. Thus, it is speculated that there are racial and ethnic differences in $\mathrm{HbA}_{1 \mathrm{c}}$ levels even among Asians, and this may be the reason for the lower threshold in our subjects. In addition, the aldehyde dehydrogenase $2 * 2(\mathrm{ALDH} 2 * 2)$ allele, which is more common in East Asians than in other ethnic groups, has been identified as a genetic risk factor for incident DR in Japanese subjects with diabetes [41], and thus, such a genetic difference in susceptibility to DR might also affect the $\mathrm{HbA}_{1 \mathrm{c}}$ levels associated with incident DR.

The use of $\mathrm{HbA}_{1 \mathrm{c}}$ measurement to diagnose diabetes remains somewhat controversial [42]. Recent epidemiological studies have revealed that $\mathrm{HbA}_{1 \mathrm{c}}$ measurement alone was less sensitive for detecting subjects with diabetes compared to the OGTT $[43,44]$. However, in our study, the AUCs for $\mathrm{HbA}_{1 \mathrm{c}}$ and FPG were not significantly different. This finding indicates that the discriminative ability of $\mathrm{HbA}_{1 \mathrm{c}}$ for diagnosing diabetes was comparable to that of FPG. Furthermore, $\mathrm{HbA}_{1 \mathrm{c}}$ measurement can be done without fasting or timed samples, and thus it would be suitable for mass screening in general practice. This advantage has implications for the early identification and treatment of undiagnosed diabetes. For these reasons, $\mathrm{HbA}_{1 \mathrm{c}}$ measurement may be an appropriate tool for detecting undiagnosed diabetes. In addition, some clinical and population-based studies, including our previous study, have shown that elevated $\mathrm{HbA}_{1 \mathrm{c}}$ levels were independently associated with cardiovascular disease $[45,46]$, suggesting that $\mathrm{HbA}_{1 \mathrm{c}}$ is also useful as a predictor of macrovascular complications. Therefore, the use of $\mathrm{HbA}_{1 \mathrm{c}}$ to diagnose diabetes will help to prevent both micro- and macrovascular complications of diabetes, which are increasingly recognized as a global health priority.

In the present analysis, although the prevalence of DR was quite small for GA below $16.2-17.5 \%$, it began to rise sharply above these levels, and the optimal threshold of GA using the ROC analysis was $17.0 \%$. Several studies have examined the use of GA levels for detecting diabetes or glucose intolerance, as defined by glucose levels. In a Japanese population study, the ROC analysis for detecting diabetes identified the GA threshold as $15.5 \%$ [23], while another study of Japanese subjects reported a GA level of $17.0 \%$ as the lower limit of glucose intolerance [21]. A similar threshold of GA was obtained in a Chinese population study (17.1\%) [22]. The thresholds in these studies were in good agreement with our findings. Together with those of other studies, our findings suggest that the optimal GA threshold for diagnosing diabetes is likely to be $17.0 \%$.

There have been a few studies evaluating the optimal threshold of 1,5-AG for identifying individuals with diabetes, as defined by a OGTT. A Japanese population study showed that $14.0 \mu \mathrm{g} / \mathrm{mL}$ was the best value for detecting subjects with diabetes [24]. Similar findings were observed among Japanese male workers $(14.2 \mu \mathrm{g} / \mathrm{mL})$ [26]. In a Chinese study, the mean of 1,5-AG levels was $15.0 \mu \mathrm{g} / \mathrm{mL}$ in subjects with newly diagnosed diabetes and $11.8 \mu \mathrm{g} / \mathrm{mL}$ in subjects with known diabetes [25]. However, no study showed an optimal threshold of 1,5AG using the presence of DR. The present study revealed that the steepest increment in the prevalence of DR occurred when the 1,5-AG levels fell below 9.6$13.5 \mu \mathrm{g} / \mathrm{mL}$, and that $12.1 \mu \mathrm{g} / \mathrm{mL}$ was the optimal $1,5-\mathrm{AG}$ threshold in the ROC analysis. Further epidemiological studies are needed to verify our findings.

The FPG of $7.0 \mathrm{mmol} / \mathrm{l}$ and the 2-hour PG of $11.1 \mathrm{mmol} / \mathrm{l}$ for diagnosing diabetes with the current criterion were also derived mainly from studies in Western populations [7]. In our study, the optimal threshold for detecting prevalent DR was $6.5 \mathrm{mmol} / \mathrm{l}$ for $\mathrm{FPG}$, and $11.5 \mathrm{mmol} / \mathrm{l}$ for 2-hour PG. The 2-hour PG threshold was compatible with that from our previous report (11.1 mmol/l) [14] and another study of a Japanese population (11.0 mmol/l) [29]. Meanwhile, other Asian population studies have reported that the optimal FPG threshold for DR was $7.0 \mathrm{mmol} / \mathrm{l}$ in a Japanese population [29], and $7.2 \mathrm{mmol} / \mathrm{l}$ in a Chinese population [17]. These findings are inconsistent with ours. However, a recent meta-analysis in Asian and Western populations evaluated the relationship of glucose levels with DR and concluded that the FPG threshold for diagnosing diabetes was $6.5 \mathrm{mmol} / \mathrm{l}$ [16]. Furthermore, our prior studies showed that the threshold of FPG for DR was $6.4 \mathrm{mmol} / \mathrm{l}[14]$ and that the FPG threshold corresponding to a 2-h PG of $11.1 \mathrm{mmol} / \mathrm{l}$ was $6.2 \mathrm{mmol} / \mathrm{l}$ [47]. These results were very similar to those of the present study. Taken together, these findings imply that, in a Japanese population, the threshold of FPG for diabetes is lower than the diagnostic criterion of $7.0 \mathrm{mmol} / \mathrm{l}$, while the threshold of 2-hour PG is $11.1 \mathrm{mmol} / \mathrm{l}$, which is in accord with the diagnostic criterion.

The present study showed that among the five glycemic measures, 2-hour PG had not only the highest sensitivity but also the largest AUC to identify the presence of DR. These results suggest that the performance and discriminative ability of 2-hour PG for diagnosing diabetes were superior to those of other glycemic measures. Oxidative stress is known to be one of the crucial contributors in the pathogenesis of DR [48]. It has also been reported that acute hyperglycemia had a more specific triggering effect on oxidative stress than chronic 
sustained hyperglycemia $[49,50]$. Thus, 2-hour PG values can be considered a better marker of oxidative stress levels arising from acute hyperglycemia than FPG, $\mathrm{HbA}_{1 \mathrm{c}}, \mathrm{GA}$, and 1,5-AG values. Furthermore, a prospective study demonstrated that postprandial plasma glucose was a stronger predictor of the progression of DR than $\mathrm{HbA}_{1 \mathrm{c}}$ in Japanese subjects with diabetes [51]. Taken together, these findings imply that 2-hour PG levels may be more strongly associated with DR than other glycemic measures. This may explain why 2-hour PG has a high diagnostic accuracy for DR. On the other hand, the AUCs for GA and 1,5-AG did not significantly differ from those for FPG and $\mathrm{HbA}_{1 \mathrm{c}}$, suggesting that GA and 1,5-AG are acceptable alternatives for the diagnosis of diabetes, and these two measures may be particularly useful for individuals with anemia, renal disease or hemoglobinopathy, for whom interpretation of $\mathrm{HbA}_{1 \mathrm{c}}$ values is problematic. However, the 1,5-AG levels had smaller AUC with lower sensitivity than other glycemic measures. One possible explanation for this phenomenon may be that 1,5-AG levels reflect the degree of glycosuria rather than glucose levels [28], while other glycemic measures directly indicate the degree of hyperglycemia. In addition, it has been reported that 1,5-AG levels were influenced by individual difference in their renal thresholds for glucose [52]. These facts might be the reason for the relatively low discriminative ability of 1,5-AG in our study.

The strengths of our study include the populationbased design, high participation rate, and availability of data to evaluate the five glycemic measures. In addition, it is noteworthy that the FPG, 2-hour PG, and $\mathrm{HbA}_{1 \mathrm{c}}$ thresholds in the present study were nearly the same as those from our previous study [14], suggesting the high reproducibility of the results in our population. However, some limitations should also be mentioned. First, our analyses included subjects with antidiabetic medications. Hypoglycemic medications could have affected the levels of glycemia. The optimal thresholds remained substantially unchanged, except for GA, after excluding subjects who received hypoglycemic medications (FPG: $6.3 \mathrm{mmol} / \mathrm{l}$; 2-hour PG: $11.5 \mathrm{mmol} / \mathrm{l} ; \mathrm{HbA}_{1 \mathrm{c}}: 6.2 \%$ [44 $\left.\mathrm{mmol} / \mathrm{mol}\right]$; GA: 20.5\%; and 1,5-AG: $12.1 \mu \mathrm{g} / \mathrm{mL}$ ). However, the precision of this finding may be limited, because of the small number of cases of DR among those not taking hypoglycemic medications. Second, the values of $\mathrm{HbA}_{1 \mathrm{c}}$ were not measured by high-performance liquid chromatography (HPLC) as used in the Diabetes Control and Complications Trial, although the method and reagent used to measure $\mathrm{HbA}_{1 \mathrm{c}}$ in this study have since been NGSP-certified. It would be preferable to measure $\mathrm{HbA}_{1 \mathrm{c}}$ by HPLC to make the results of our study more comparable to those of other studies. Third, the GA and 1,5-AG levels were measured in serum conserved at $-80^{\circ} \mathrm{C}$ for 5 years. However, the stability of GA and
1,5-AG measurements in frozen stored serum sample was preserved [53,54]. Fourth, this study is a crosssectional design, which might have affected the threshold values of glycemic measures. Diagnostic thresholds would ideally be derived from prospective studies that examine the relationship between measures of glycemia and incident microvascular complications. Lastly, the influence of factors that may affect $\mathrm{HbA}_{1 \mathrm{c}}$ levels, such as anemia, renal failure, and hemoglobinopathy should be considered. We performed sensitivity analyses excluding subjects with anemia or renal failure, and the optimal threshold of $\mathrm{HbA}_{1 \mathrm{c}}$ remained unchanged (6.1\% [ $43 \mathrm{mmol} / \mathrm{mol}])$. Furthermore, the prevalence of hemoglobinopathy in Japan was reported to be very low $(0.04 \%)$ [55]. Therefore, the influence of this limitation would have been small.

\section{Conclusions}

The present analysis showed that, in a Japanese population, the FPG and $\mathrm{HbA}_{1 \mathrm{c}}$ threshold for diagnosing diabetes was lower than the current diagnostic criterion, while the 2-hour PG threshold was consistent with the diagnostic criterion, and the discriminative ability of $2-$ hour PG was superior to other glycemic measures. These findings suggest that the threshold of 2-hour PG is $11.1 \mathrm{mmol} / \mathrm{l}$, regardless of race, whereas ethnic-specific thresholds of FPG and $\mathrm{HbA}_{1 \mathrm{c}}$ may be necessary. This study also demonstrated the potential applicability of GA and 1,5-AG measurements as a diagnostic tool for diabetes. Further prospective studies are needed to verify these findings, and investigations of $\mathrm{HbA}_{1 \mathrm{c}}$ levels in the intermediate range are also required.

\section{Abbreviations \\ $\mathrm{HbA}_{1 c}$ : Hemoglobin $\mathrm{A}_{1}$; DR: Diabetic retinopathy; FPG: Fasting plasma glucose; GA: Glycated albumin; 1,5-AG: 1,5-anhydroglucitol; PG: Postload glucose; OGTT: Oral glucose tolerance test; Hb: Hemoglobin; NGSP: National Glycohemoglobin Standardization Program; JDS: Japan Diabetes Society; eGFR: Estimated glomerular filtration rate; BMI: Body mass index; ETDRS: Early Treatment of Diabetic Retinopathy Study; ROC: Receiver operating characteristic; AUC: Area under the receiver operating characteristic curve: Cl: Confidence interval; HPLC: High-performance liquid chromatography.}

Competing interests

The authors declare that they have no competing interests.

\section{Authors' contributions}

NM contributed to the study concept and design, data collection, data analysis, data interpretation, and drafting of the manuscript. MY contributed to the data collection, data interpretation, and drafting of the manuscript

$\mathrm{TN}, J \mathrm{H}, \mathrm{YH}, \mathrm{Fl}$, and MF contributed to the data collection and data interpretation. TH and DK measured the samples and contributed to the data interpretation. MK, UN, and TK contributed to the data interpretation and the critical revision of the manuscript for important intellectual content. YK contributed to the data collection, data interpretation, drafting of the manuscript, obtained funding, and study supervision. All authors provided critical review of the draft and approved the final version.

\section{Acknowledgments}

The authors thank the staff of the Division of Health and Welfare of Hisayama for their cooperation in this study. 
This study was supported in part by Grants-in-Aid for Scientific Research on Innovative Areas (22116010) and for Scientific Research (A) (25253048 and 22240073), (B) (25293428), and (C) (23590797, 23590798, 23500842, 24590796, 24590797, and 25460758) from the Ministry of Education, Culture, Sports, Science and Technology of Japan, by Health and Labour Sciences Research Grants of the Ministry of Health, Labour and Welfare of Japan (Comprehensive Research on Life-Style Related Diseases including Cardiovascular Diseases and Diabetes Mellitus: H22-Junkankitou [Seishuu]-Ippan-005, H23-Junkankitou [Seishuu]-Ippan-005, H25-Junkankitou [Seishuu]-Ippan-005, H25-Junkankitou [Seishuu]-Ippan-009, and H25-Junkankitou [Seishuu]-Sitei-022; and Comprehensive Research on Dementia: H25-Ninchisho-Ippan-004), and by a research grant from the Japan Diabetes Society.

\section{Author details}

'Department of Environmental Medicine, Graduate School of Medical Sciences, Kyushu University, 3-1-1 Maidashi, Higashi-ku, Fukuoka 812-8582, Japan. ${ }^{2}$ Department of Medicine and Clinical Science, Graduate School of Medical Sciences, Kyushu University, Fukuoka, Japan. ${ }^{3}$ Department of Ophthalmology, Graduate School of Medical Sciences, Kyushu University, Fukuoka, Japan. ${ }^{4}$ Department of Clinical Chemistry and Laboratory Medicine, Kyushu University Hospital, Fukuoka, Japan. ${ }^{5}$ Department of Internal Medicine, Kawanishi City Hospital, Hyogo, Japan.

Received: 5 December 2013 Accepted: 12 February 2014 Published: 17 February 2014

\section{References}

1. International Expert Committee: International expert committee report on the role of the A1C assay in the diagnosis of diabetes. Diabetes Care 2009, 32:1327-1334.

2. Gillett MJ: International expert committee report on the role of the A1C assay in the diagnosis of diabetes: Diabetes Care 2009; 32(7): 1327-1334. Clin Biochem Rev 2009, 30:197-200.

3. American Diabetes Association: Diagnosis and classification of diabetes mellitus. Diabetes Care 2010, 33(Suppl 1):S62-S69.

4. World Health Organization: Use of glycated haemoglobin (HbA1c) in the diagnosis of diabetes mellitus. 2011.

5. McCance DR, Hanson RL, Charles MA, Jacobsson LT, Pettitt DJ, Bennett PH, Knowler WC: Comparison of tests for glycated haemoglobin and fasting and two hour plasma glucose concentrations as diagnostic methods for diabetes. BMJ 1994, 308:1323-1328.

6. Engelgau MM, Thompson TJ, Herman WH, Boyle JP, Aubert RE, Kenny SJ, Badran A, Sous ES, Ali MA: Comparison of fasting and 2-hour glucose and $\mathrm{HbA}_{1 \mathrm{c}}$ levels for diagnosing diabetes. Diagnostic criteria and performance revisited. Diabetes Care 1997, 20:785-791.

7. The Expert Committee on the diagnosis and classification of diabetes mellitus: Report of the Expert Committee on the diagnosis and classification of diabetes mellitus. Diabetes Care 1997, 20:1183-1197.

8. Pang C, Jia L, Jiang S, Liu W, Hou X, Zuo Y, Gu H, Bao Y, Wu Q, Xiang K, Gao $X$, Jia W: Determination of diabetic retinopathy prevalence and associated risk factors in Chinese diabetic and pre-diabetic subjects: Shanghai diabetic complications study. Diabetes Metab Res Rev 2012, 28:276-283.

9. The Diabetes Control and Complications Trial Research Group: The effect of intensive treatment of diabetes on the development and progression of long-term complications in insulin-dependent diabetes mellitus. N Engl J Med 1993, 329:977-986.

10. UK Prospective Diabetes Study (UKPDS) Group: Intensive blood-glucose control with sulphonylureas or insulin compared with conventional treatment and risk of complications in patients with type 2 diabetes (UKPDS 33). Lancet 1998, 352:837-853.

11. Ismail-Beigi F, Craven T, Banerji MA, Basile J, Calles J, Cohen RM, Cuddihy R, Cushman WC, Genuth S, Grimm RH Jr, Hamilton BP, Hoogwerf B, Karl D, Katz L, Krikorian A, O'Connor P, Pop-Busui R, Schubart U, Simmons D, Taylor $H$, Thomas A, Weiss D, Hramiak I: Effect of intensive treatment of hyperglycaemia on microvascular outcomes in type 2 diabetes: an analysis of the ACCORD randomised trial. Lancet 2010, 376:419-430.

12. Wong TY, Liew G, Tapp RJ, Schmidt MI, Wang JJ, Mitchell P, Klein R, Klein $B E$, Zimmet P, Shaw J: Relation between fasting glucose and retinopathy for diagnosis of diabetes: three population-based cross-sectional studies. Lancet 2008, 371:736-743.
13. Massin $P$, Lange $C$, Tichet J, Vol S, Erginay A, Cailleau M, Eschwège E, Balkau $B$ : Hemoglobin $A_{1 c}$ and fasting plasma glucose levels as predictors of retinopathy at 10 years: the French DESIR study. Arch Ophthalmol 2011, 129:188-195.

14. Miyazaki M, Kubo M, Kiyohara Y, Okubo K, Nakamura H, Fujisawa K, Hata Y, Tokunaga S, lida M, Nose Y, Ishibashi T: Comparison of diagnostic methods for diabetes mellitus based on prevalence of retinopathy in a Japanese population: the Hisayama Study. Diabetologia 2004, 47:1411-1415.

15. Sabanayagam C, Liew G, Tai ES, Shankar A, Lim SC, Subramaniam T, Wong TY: Relationship between glycated haemoglobin and microvascular complications: is there a natural cut-off point for the diagnosis of diabetes? Diabetologia 2009, 52:1279-1289.

16. Colagiuri S, Lee CM, Wong TY, Balkau B, Shaw JE, Borch-Johnsen K. Glycemic thresholds for diabetes-specific retinopathy: implications for diagnostic criteria for diabetes. Diabetes Care 2011, 34:145-150.

17. Xin Z, Yuan MX, Li HX, Hua L, Feng JP, Shi J, Zhu XR, Cao X, Yang JK: Evaluation for fasting and 2-hour glucose and $\mathrm{HbA}_{1 c}$ for diagnosing diabetes based on prevalence of retinopathy in a Chinese population. PLoS One 2012, 7:e40610.

18. Ito C: Evidence for diabetes mellitus criteria in 2010 using $\mathrm{HbA} 1 \mathrm{c}$. Diabetol Int 2013, 4:9-15.

19. Selvin E, Francis LM, Ballantyne CM, Hoogeveen RC, Coresh J, Brancati FL, Steffes MW: Nontraditional markers of glycemia: associations with microvascular conditions. Diabetes Care 2011, 34:960-967.

20. Kim WJ, Park CY, Park SE, Rhee EJ, Lee WY, Oh KW, Park SW, Kim SW, Park HS, Kim YJ, Song SJ, Ahn HY: Serum 1,5-anhydroglucitol is associated with diabetic retinopathy in type 2 diabetes. Diabet Med 2012, 29:1184-1190.

21. Tominaga M, Makino H, Yoshino G, Kuwa K, Takei I, Aono Y, Hoshino T, Umemoto M, Shimatsu A, Sanke T, Kuwashima M, Taminato T, Ono J: Report of the committee on standardization of laboratory testing related to diabetes mellitus of the Japan Diabetes Society: determination of reference intervals of hemoglobin $A_{1 C}$ (IFCC) and glycoalbumin in the Japanese population. J Japan Diab Soc 2006, 49:825-833 (in Japanese).

22. Ma XJ, Pan JM, Bao YQ, Zhou J, Tang JL, Li Q, Xiang KS, Jia WP: Combined assessment of glycated albumin and fasting plasma glucose improves the detection of diabetes in Chinese subjects. Clin Exp Pharmacol Physiol 2010, 37:974-979.

23. Furusyo N, Koga T, Ai M, Otokozawa S, Kohzuma T, Ikezaki H, Schaefer EJ, Hayashi J: Utility of glycated albumin for the diagnosis of diabetes mellitus in a Japanese population study: results from the Kyushu and Okinawa Population Study (KOPS). Diabetologia 2011, 54:3028-3036.

24. Yamanouchi T, Akanuma Y, Toyota T, Kuzuya T, Kawai T, Kawazu S, Yoshioka S, Kanazawa Y, Ohta M, Baba S, Kosaka K: Comparison of 1,5-anhydroglucitol, $\mathrm{HbA}_{1 c}$ and fructosamine for detection of diabetes mellitus. Diabetes 1991, 40:52-57.

25. Robertson DA, Alberti KG, Dowse GK, Zimmet P, Tuomilehto J, Gareeboo H: Is serum anhydroglucitol an alternative to the oral glucose tolerance test for diabetes screening? Diabet Med 1993, 10:56-60.

26. Goto M, Yamamoto-Honda R, Shimbo T, Goto A, Terauchi Y, Kanazawa Y, Noda M: Correlation between baseline serum 1,5-anhydroglucitol levels and 2-hour post-challenge glucose levels during oral glucose tolerance tests. Endocr J 2011, 58:13-17.

27. Koga M, Kasayama $\mathrm{S}$ : Clinical impact of glycated albumin as another glycemic control marker. Endocr J 2010, 57:751-762.

28. Kim WJ, Park CY: 1,5-anhydroglucitol in diabetes mellitus. Endocrine 2013, 43:33-40.

29. Ito C, Maeda R, Ishida S, Harada H, Inoue N, Sasaki H: Importance of OGTT for diagnosing diabetes mellitus based on prevalence and incidence of retinopathy. Diabetes Res Clin Pract 2000, 49:181-186.

30. Fukuhara M, Arima H, Ninomiya T, Hata J, Hirakawa Y, Doi Y, Yonemoto K, Mukai N, Nagata M, Ikeda F, Matsumura K, Kitazono T, Kiyohara Y: White-coat and masked hypertension are associated with carotid atherosclerosis in a general population: the Hisayama Study. Stroke 2013, 44:1512-1517

31. Hata J, Ninomiya T, Hirakawa Y, Nagata M, Mukai N, Gotoh S, Fukuhara M, Ikeda F, Shikata K, Yoshida D, Yonemoto K, Kamouchi M, Kitazono T, Kiyohara Y: Secular trends in cardiovascular disease and its risk factors in Japanese: half century data from the Hisayama Study, 1961-2009. Circulation 2013, 128:1198-1205. 
32. Alberti $K G$, Zimmet $P Z$ : Definition, diagnosis and classification of diabetes mellitus and its complications. Part 1: diagnosis and classification of diabetes mellitus provisional report of a WHO consultation. Diabet Med 1998, 15:539-553.

33. Committee on the standardization of diabetes mellitus-related laboratory testing of Japan Diabetes Society: International clinical harmonization of glycated hemoglobin in Japan: from Japan Diabetes Society to National Glycohemoglobin Standardization Program values. J Diabetes Invest 2012, 3:39-40.

34. World Health Organization: Haemoglobin concentrations for the diagnosis of anaemia and assessment of severity. Vitamin and Mineral Nutrition Information System. Geneva: World Health Organization; 2011.

35. Matsuo S, Imai E, Horio M, Yasuda Y, Tomita K, Nitta K, Yamagata K, Tomino $Y$, Yokoyama $H$, Hishida A: Revised equations for estimated GFR from serum creatinine in Japan. Am J Kidney Dis 2009, 53:982-992.

36. National Kidney Foundation: K/DOQI clinical practice guidelines for chronic kidney disease: evaluation, classification, and stratification. Am J Kidney Dis 2002, 39:S1-S266.

37. Wilkinson CP, Ferris FL III, Klein RE, Lee PP, Agardh CD, Davis M, Dills D, Kampik A, Pararajasegaram R, Verdaguer JT: Proposed international clinical diabetic retinopathy and diabetic macular edema disease severity scales. Ophthalmology 2003, 110:1677-1682.

38. DeLong ER, DeLong DM, Clarke-Pearson DL: Comparing the areas under two or more correlated receiver operating characteristic curves: a nonparametric approach. Biometrics 1988, 44:837-845.

39. Likhari T, Gama R: Glycaemia-independent ethnic differences in $\mathrm{HbA}_{1 \mathrm{c}}$ in subjects with impaired glucose tolerance. Diabet Med 2009, 26:1068-1069.

40. Davidson MB, Schriger DL: Effect of age and race/ethnicity on $\mathrm{HbA1c}$ levels in people without known diabetes mellitus: implications for the diagnosis of diabetes. Diabetes Res Clin Pract 2010, 87:415-421.

41. Morita K, Saruwatari J, Miyagawa H, Uchiyashiki Y, Oniki K, Sakata M, Kajiwara A, Yoshida A, Jinnouchi H, Nakagawa K: Association between aldehyde dehydrogenase 2 polymorphisms and the incidence of diabetic retinopathy among Japanese subjects with type 2 diabetes mellitus. Cardiovasc Diabetol 2013, 12:132.

42. Waugh NR, Shyangdan D, Taylor-Phillips S, Suri G, Hall B: Screening for type 2 diabetes: a short report for the National Screening Committee. Health Technol Assess 2013, 17:1-90.

43. Kramer CK, Araneta MR, Barrett-Connor E: A1C and diabetes diagnosis: the Rancho Bernardo study. Diabetes Care 2010, 33:101-103.

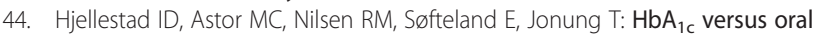
glucose tolerance test as a method to diagnose diabetes mellitus in vascular surgery patients. Cardiovasc Diabetol 2013, 12:79.

45. Penno G, Solini A, Zoppini G, Orsi E, Fondelli C, Zerbini G, Morano S, Cavalot F, Lamacchia O, Trevisan R, Vedovato M, Pugliese G: Hemoglobin $A_{1 c}$ variability as an independent correlate of cardiovascular disease in patients with type 2 diabetes: a cross-sectional analysis of the Renal Insufficiency and Cardiovascular Events (RIACE) Italian multicenter study. Cardiovasc Diabetol 2013, 12:98

46. Ikeda F, Doi Y, Ninomiya T, Hirakawa Y, Mukai N, Hata J, Shikata K, Yoshida D, Matsumoto T, Kitazono T, Kiyohara Y: Haemoglobin A1c even within non-diabetic level is a predictor of cardiovascular disease in a general Japanese population: the Hisayama study. Cardiovasc Diabetol 2013, 12:164.

47. Doi Y, Kubo M, Yonemoto K, Ninomiya T, Iwase M, Arima H, Hata J, Tanizaki Y, lida M, Kiyohara Y: Fasting plasma glucose cutoff for diagnosis of diabetes in a Japanese population. J Clin Endocrinol Metab 2008, 93:3425-3429.

48. Madsen-Bouterse SA, Kowluru RA: Oxidative stress and diabetic retinopathy: pathophysiological mechanisms and treatment perspectives. Rev Endocr Metab Disord 2008, 9:315-327.

49. Monnier L, Mas E, Ginet C, Michel F, Villon L, Cristol JP, Colette C: Activation of oxidative stress by acute glucose fluctuations compared with sustained chronic hyperglycemia in patients with type 2 diabetes. JAMA 2006, 295:1681-1687.

50. Ceriello A, Esposito K, Piconi L, Ihnat MA, Thorpe JE, Testa R, Boemi M, Giugliano D: Oscillating glucose is more deleterious to endothelial function and oxidative stress than mean glucose in normal and type 2 diabetic patients. Diabetes 2008, 57:1349-1354.

51. Shiraiwa T, Kaneto H, Miyatsuka T, Kato K, Yamamoto K, Kawashima A, Kanda T, Suzuki M, Imano E, Matsuhisa M, Hori M, Yamasaki Y: Postprandial hyperglycemia is a better predictor of the progression of diabetic retinopathy than $\mathrm{HbA}_{1 \mathrm{c}}$ in Japanese type 2 diabetic patients. Diabetes Care 2005, 28:2806-2807.

52. Kilpatrick ES, Keevilt BG, Richmond KL, Newland P, Addison GM: Plasma 1,5-anhydroglucitol concentrations are influenced by variations in the renal threshold for glucose. Diabet Med 1999, 16:496-499.

53. Nowatzke W, Sarno MJ, Birch NC, Stickle DF, Eden T, Cole TG: Evaluation of an assay for serum 1,5-anhydroglucitol (GlycoMark ${ }^{\top M}$ ) and determination of reference intervals on the Hitachi 917 analyzer. Clin Chim Acta 2004 350:201-209.

54. Nathan DM, Steffes MW, Sun W, Rynders GP, Lachin JM: Determining stability of stored samples retrospectively: the validation of glycated albumin. Clin Chem 2011, 57:286-290.

55. Harano T: Hemoglobinopathy in Japan: detection and analysis. Rinsho Byori 1999, 47:215-223 (in Japanese).

doi:10.1186/1475-2840-13-45

Cite this article as: Mukai et al:: Thresholds of various glycemic measures for diagnosing diabetes based on prevalence of retinopathy in community-dwelling Japanese subjects: the Hisayama Study. Cardiovascular Diabetology):2014 13:45

\section{Submit your next manuscript to BioMed Central and take full advantage of:}

- Convenient online submission

- Thorough peer review

- No space constraints or color figure charges

- Immediate publication on acceptance

- Inclusion in PubMed, CAS, Scopus and Google Scholar

- Research which is freely available for redistribution

Submit your manuscript at www.biomedcentral.com/submit
C BioMed Central 